\title{
Environmental Signals Modulate Olfactory Acuity, Discrimination, and Memory in Caenorhabditis elegans
}

\author{
Heather A. Colbert and Cornelia I. Bargmann ${ }^{1}$ \\ Howard Hughes Medical Institute \\ Programs in Developmental Biology, Neuroscience, and Genetics \\ Department of Anatomy \\ The University of California \\ San Francisco, California 94143-0452
}

\begin{abstract}
Caenorbabditis elegans uses a variety of attractive olfactory cues to detect food. We show here that the responses to olfactory cues are regulated in a dynamic way by behavioral context and the animal's previous experience. Prolonged exposure to an odorant leads to a decreased response to that odorant, a form of behavioral plasticity called olfactory adaptation. We show that starvation can increase the extent of olfactory adaptation to the odorant benzaldehyde; this effect of starvation persists for several hours after the animals have been returned to food. The effect of starvation is antagonized by exogenous serotonin, which induces many of the same behavioral responses in $C$. elegans as are induced by food. Starvation also inhibits recovery from adaptation to a different odorant, 2-methylpyrazine, thus enhancing olfactory memory. In addition to its effects on adaptation, starvation modulates olfactory discrimination in C. elegans; starved animals discriminate more classes of odorants than fed animals. Increased olfactory discrimination is also seen in the adaptation-defective mutant adp-1(ky20). These various forms of behavioral plasticity enhance the ability of starved animals to respond to novel, potentially informative odorants.
\end{abstract}

\footnotetext{
${ }^{1}$ Corresponding author.
}

\section{Introduction}

Animals respond to environmental signals by modifying their behavior. For example, the nematode Caenorbabditis elegans decreases its response to an odorant following prolonged exposure to that odorant (Colbert and Bargmann 1995); this behavioral modification constitutes a primitive form of memory. Mutants that have specific defects in olfactory adaptation while retaining normal olfactory acuity have been identified (Colbert and Bargmann 1995). Interestingly, adaptation to different odorants requires different genes; for example, the adp-1(ky20) mutation affects adaptation to some odorants but not others. Although the mechanisms of adaptation are not fully understood, calcium influx has been shown to play a crucial role in the ability of animals to remember previous odorant exposure (Colbert and Bargmann 1995), and a putative ion channel with structural similarity to the Drosophila TRP channel may mediate some forms of olfactory adaptation (H.A. Colbert, T. Smith, and C.I. Bargmann, in prep.).

Environmental cues also modulate other aspects of $C$. elegans behavior. For example, $C$. elegans's thermal preferences are modified by the animal's experience (Hedgecock and Russell 1975; Mori and Ohshima 1995), as are touch (Rankin et al. 1990) and taste responses (Ward 1973; Dusenbery 1980). C. elegans's feeding state also modulates several of the animal's behaviors: The presence of food stimulates defecation (Liu and Thomas 1994), pharyngeal pumping (Avery and Horvitz 1990), and egg laying (Horvitz et al. 1982; Trent 1982; Weinshenker et al. 1995), but inhibits locomotion (Croll 1975). The neurotransmitter serotonin has been detected in $C$. elegans by formal-

LEARNING \& MEMORY 4:179-191 (c) 1997 by Cold Spring Harbor Laboratory Press ISSN1072-0502/97 \$5.00

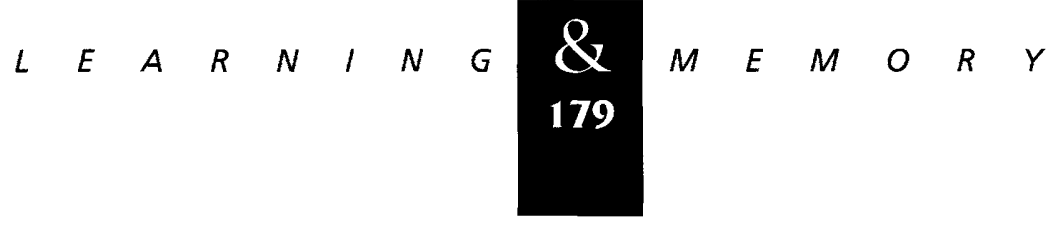


dehyde-induced fluorescence and by immunocytological methods (Horvitz et al. 1982; Desai et al. 1988; Loer and Kenyon 1993); serotonin has been proposed to function both as a neurotransmitter and as a neurohormone to regulate several $C$. elegans behaviors. Exposure to exogenous serotonin mimics the effects of food in several respects: It stimulates pharyngeal pumping (Avery and Horvitz 1990), as well as egg laying (Horvitz et al. 1982; Trent et al. 1983; Schafer and Kenyon 1995), but inhibits locomotion (Horvitz et al. 1982; Schafer and Kenyon 1995). Serotonin may therefore mediate some of the effects of food on behavior. The effects of serotonin on locomotion and egg laying are thought to be mediated by the G protein $\alpha$-subunit encoded by goa-1, which is expressed in all neurons and some muscles (Mendel et al. 1995; Segalat et al. 1995).

Serotonin functions as a neuromodulator and a neurohormone in many other vertebrate and invertebrate systems; the role of serotonin in modulating synaptic plasticity has been well documented. In the gill-withdrawal reflex pathway of Aplysia, serotonin enhances short-term presynaptic facilitation by modulating potassium conductances and enhancing neurotransmitter release in sensory neurons (for review, see Byrne and Kandel 1996); serotonin also regulates neurotransmitter release at the crayfish neuromuscular junction (Delaney et al. 1991). Serotonin functions as a neuromodulator in the olfactory systems of invertebrates (Gelperin et al. 1993; Kloppenburg and Hildebrand 1995; Mercer et al. 1995) and has been implicated in olfactory learning in rat pups (McLean et al. 1993).

We were interested in determining whether olfactory memory and discrimination are modulated by environmental signals in C. elegans. Psychophysical studies in humans have suggested a link between starvation and olfactory acuity, although this has been controversial (Koelega 1994); habituation to food cues in humans is modulated by environmental signals (Epstein et al. 1992). Little is known, however, about the mechanistic basis for modulation of olfactory responses by feeding state or other environmental cues. C. elegans is an ideal system in which to address these questions owing to the simplicity and genetic tractability of its olfactory system. C. elegans uses two pairs of olfactory sensory neurons, designated AWA and AWC, to discriminate at least seven classes of volatile odorants; a single odorant can be detected over a concentration range of a millionfold (Bargmann et al. 1993). Olfactory adaptation in C. elegans in- volves odorant-selective pathways; adaptation to one odorant does not affect the response to other odorants sensed by the same olfactory neuron (Colbert and Bargmann 1995).

Here, we show that olfactory memory in $C$. elegans is enhanced by starvation, whereas olfactory sensitivity is largely unaffected; exposure to exogenous serotonin inhibits this effect of starvation. Starvation also enhances the ability of $C$. elegans to discriminate among odorants, as does the mutation adp-1(ky20), which inhibits some forms of adaptation. Finally, adaptation to one odorant increases sensitivity to another odorant sensed by the same olfactory neuron.

\section{Materials and Methods}

\section{STRAINS}

Wild-type worms were $C$. elegans variety Bristol, strain N2. Worms were grown to adulthood under unstarved conditions at $20^{\circ} \mathrm{C}$ or $25^{\circ} \mathrm{C}$ using standard methods (Brenner 1974). The strain CX20 adp-1(ky20) II was used in this work (Colbert and Bargmann 1995).

\section{BEHAVIORAL ASSAYS}

Population chemotaxis assays were conducted using standard techniques (Bargmann et al. 1993): Several hundred animals were washed twice with $S$ Basal and once with assay buffer (same composition as assay plates but without agar). They were then transferred to the middle of a $10-\mathrm{cm}$ assay plate containing $10 \mathrm{ml}$ of agar (1.6\% agar, $5 \mathrm{~mm} \mathrm{KPO}_{4}$ at $\mathrm{pH} \mathrm{6,1} \mathrm{mm} \mathrm{CaCl}_{2}, 1 \mathrm{~mm} \mathrm{MgSO}_{4}$ ). One microliter of diluted odorant was placed at one end of the plate with $1 \mu$ l of diluent (ethanol) at the other end of the plate. One microliter of $1 \mathrm{M}$ $\mathrm{NaN}_{3}$ was placed at each end of the plate to paralyze the animals upon arrival at either the odorant or the diluent. Assays were conducted for $60 \mathrm{~min}$; only adult animals were scored in all assays. The chemotaxis index (CI) was calculated as follows: $\mathrm{CI}=$ (no. at attractant $)-($ no. at diluent $) /$ total no. of animals tested. Unless otherwise noted, odorant concentrations (vol/vol) used for assays were benzaldehyde, 1:200; butanone, 1:1000; isoamyl alcohol, 1:100; 2-methylpyrazine, 1:1000; and diacetyl, 1:1000. Odorants were diluted in ethanol.

Adaptation assays were performed as described in Colbert and Bargmann (1995): Animals

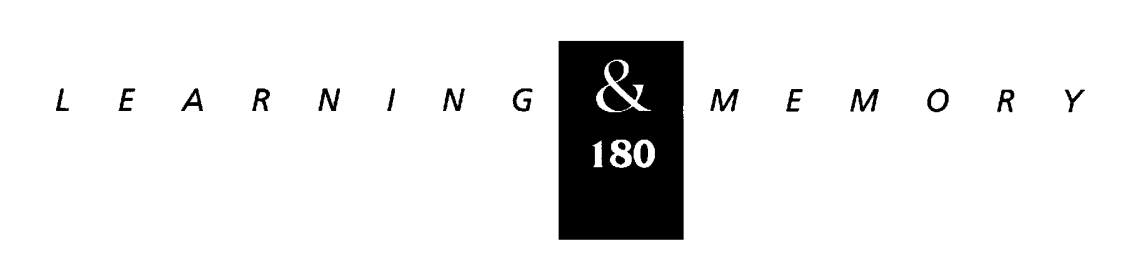


were washed twice with S Basal and once with assay buffer and were transferred to a $10-\mathrm{cm}$ plate containing $10 \mathrm{ml}$ of agar (3\% agar, $5 \mathrm{~mm} \mathrm{KPO}_{4}$ at pH 6.0, $1 \mathrm{~mm} \mathrm{CaCl}_{2}, 1 \mathrm{~mm} \mathrm{MgSO}_{4}$ ). Odorant was distributed among five agar plugs on the lid of the plate (or not); the plate was sealed with Parafilm. After adaptation for the designated time, the animals were washed three times with $\mathrm{S}$ Basal and once with assay buffer, and chemotaxis assays were performed as described. The amounts of odorants used for adaptations were $3 \mu$ l of benzaldehyde, $15 \mu \mathrm{l}$ of isoamyl alcohol, or $1 \mu \mathrm{l}$ of 2-methylpyrazine. Adaptations were performed in the absence of food.

Food was prepared by growing Escherichia coli (HB101) to saturation in 2 liters of LB media; the bacteria were subsequently spun down and resuspended in $40 \mathrm{ml}$ of $\mathrm{H}_{2} \mathrm{O}$. For incubations with food, three $20-\mu$ drops of food were distributed over $3 \%$ assay plates and animals were then transferred to these plates.

Starvation time courses were performed as follows: Animals were washed twice with S Basal and once with assay buffer and were transferred to $3 \%$ assay plates (same composition as assay plates except with 3\% agar) on which they were maintained with food. At various times, animals were washed three times and transferred to 3\% assay plates without food. After the designated starvation period had elapsed, odorant was distributed over the lid of the assay plates (or not) and the subsequent adaptation and assays were performed as described (Colbert and Bargmann 1995).

Starvation assays presented in Figure 2, B and $\mathrm{C}$, below, were conducted in a similar way: Animals were washed and transferred to $3 \%$ assay plates with or without food. After $2 \mathrm{hr}$, they were washed again and transferred to $3 \%$ assay plates on which they were adapted (or not) and assayed.

Recovery from starvation presented in Figure 1B was assayed as follows: Animals were washed three times and transferred to $3 \%$ assay plates with food. At various times, they were washed and transferred to $3 \%$ assay plates on which they were starved for $2 \mathrm{hr}$. Subsequently, food was added to the plates, and the animals were allowed to recover for the designated time periods. They were then washed, adapted, and assayed. Fed animals were treated identically except they were not starved.

Dose-response curves on fed versus starved animals were performed by washing animals, transferring them to $3 \%$ assay plates with or without food for $2 \mathrm{hr}$, washing them again, and assaying their response to various dilutions of odorant.

To assay the effects of exogenous serotonin on starved and fed animals, animals were washed and transferred to $3 \%$ assay plates containing $5 \mathrm{~mm}$ serotonin (or not). Food was added to these plates (or not) and the animals were incubated for $2 \mathrm{hr}$. They were then washed, adapted (or not), and assayed. Two millimolar serotonin gave a similar effect to $5 \mathrm{~mm}$ serotonin, whereas $1 \mathrm{~mm}$ serotonin produced an intermediate effect on adaptation of starved animals (data not shown). Animals were also transferred to phentolamine-containing plates (at concentrations of $2 \mathrm{mg} / \mathrm{ml}, 1.5 \mathrm{mg} / \mathrm{ml}$, and 1 $\mathrm{mg} / \mathrm{ml}$ ), incubated for $2 \mathrm{hr}$, and subsequently washed, adapted, and assayed. Preincubation with the octopamine antagonist phentolamine produced no effect on adaptation (data not shown).

To determine whether exogenous serotonin was sufficient to reverse the effect of starvation on benzaldehyde adaptation, animals were starved for $2 \mathrm{hr}$ and then transferred to plates containing food, $5 \mathrm{~mm}$ serotonin, or neither food nor serotonin for 3 hr. They were then adapted and assayed. No effect was seen following shorter incubations on serotonin-containing plates (data not shown). Combinations of $5 \mathrm{~mm}$ serotonin and $1 \mathrm{mg} / \mathrm{ml}$ of phentolamine, or $5 \mathrm{~mm}$ serotonin and $1 \mathrm{~mm}$ carbachol also failed to reverse the effect of starvation on benzaldehyde adaptation (data not shown).

Cross-saturation assays were performed as follows: Animals were washed and transferred to $3 \%$ assay plates containing $1 \mu \mathrm{l}$ of benzaldehyde per 10 $\mathrm{ml}$ of agar for $5 \mathrm{~min}$. They were then washed and assayed on plates with lids containing 15 agar plugs $(0.8 \mathrm{~cm}$ diam.) taken from an assay plate containing $1 \mu \mathrm{l}$ of benzaldehyde per $10 \mathrm{ml}$ of agar. These agar plugs were positioned in such a way as to provide a relatively high uniform concentration of benzaldehyde across the entire assay plate. For the assays presented in Figure 5A, below, the animals were first washed and transferred to $3 \%$ assay plates with or without food for $2 \mathrm{hr}$, and then assayed as described above. Saturation with isoamyl alcohol also cross-saturates the response to benzaldehyde: A similar protocol involving exposure to 1 $\mu \mathrm{l}$ of isoamyl alcohol reduced the isoamyl alcohol chemotaxis index from 0.85 to -0.04 (four and six assays, respectively, $t=8.46, P<0.001$ ), and the benzaldehyde chemotaxis index from 0.84 to 0.35 (five and seven assays, respectively, $t=3.45$, $P=0.006)$.

To determine the time course of recovery from

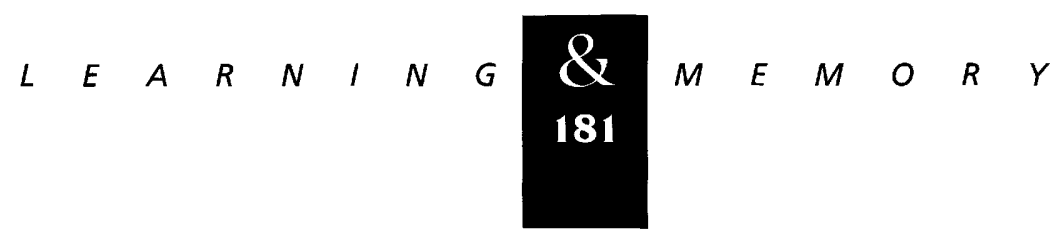


2-methylpyrazine adaptation, animals were incubated with or without 2-methylpyrazine for $10 \mathrm{~min}$ and then washed and allowed to recover on 3\% assay plates containing food for various lengths of time; they were then assayed for their response to 2-methylpyrazine or to the control odorant diacetyl.

Assays of the effect of starvation on recovery from olfactory adaptation were conducted as follows: Animals were adapted to an odorant, washed, and transferred to $3 \%$ assay plates with or without food. After the stated recovery time period, they were assayed for their odorant responses.

Assays of olfactory acuity following odorant exposure were performed as follows: Animals were exposed to the adapting odorant as described, then washed, divided, and assayed in par-

Figure 1: Starvation enhances adaptation to benzaldehyde. (A) Time course of starvation. Animals were starved for various lengths of time and were then incubated with (solid lines) or without (broken lines) benzaldehyde for $60 \mathrm{~min}$. Subsequently, they were assayed for their response to benzaldehyde or to the control odorant butanone (inset). Animals starved for $30 \mathrm{~min}$ responded similarly to unstarved animals $(t=2.03, P>0.05$ by Bonferroni $t$-test with 25 degrees of freedom), whereas animals starved for 60 min or longer exhibited enhanced adaptation [marked with asterisks $\left({ }^{*}\right)$; unstarved vs. 60 min: $t=6.36, P<0.05$; unstarved vs. $90 \mathrm{~min}: t=7.12, P<0.05$; unstarved vs. $120 \mathrm{~min}: t=7.38, P<0.05$; starved $30 \mathrm{~min}$ vs. $60 \min : t=4.33, P<0.05$, starved $30 \mathrm{~min}$ vs. $90 \mathrm{~min}: t=5.09$, $P<0.05$; starved $30 \mathrm{~min}$ vs. $120 \mathrm{~min}: t=5.34, P<0.05$; starved $60 \mathrm{~min}$ vs. $120 \mathrm{~min}: t=1.018, P>0.05]$. For all time points, adapted animals are different from unadapted control animals at $P<0.001$ by $t$-test. $(B)$ Time course of recovery from starvation. Animals were starved for $2 \mathrm{hr}$, allowed to recover in the presence of food for various lengths of time, and then incubated with (solid lines) or without (broken lines) benzaldehyde for $60 \mathrm{~min}$. They were subsequently assayed for their response to benzaldehyde or to the control odorant butanone (inset). The rightmost point on the graph represents the behavior of unstarved animals that were incubated with benzaldehyde for $60 \mathrm{~min}$ and then assayed for their response to benzaldehyde or butanone (inset). Animals that were recovered in the presence of food for $3 \mathrm{hr}$ or longer adapted significantly less than starved animals [marked with asterisks $\left(^{*}\right)$; by Bonferroni $t$-test, 30 degrees of freedom for all data points: for $3 \mathrm{hr}$, $t=9.974, P<0.05$; for $4 \mathrm{hr}, t=10.579, P<0.05]$. After shorter incubations with food, responses were similar to those of starved animals (for $1 \mathrm{hr}, t=1.455, P>0.05$; for $2 \mathrm{hr}, t=3.022, P>0.05$ ). Conversely, shorter incubations with food led to responses distinct from those of fed animals (for $1 \mathrm{hr}, t=7.556, P<0.05$; for $2 \mathrm{hr}, t=6.045, P<0.05$ ), but long incubations in food led to responses similar to those of fed animals (for $3 \mathrm{hr}, t=0.853, P>0.05 ;$ for $4 \mathrm{hr}, t=1.511$, $P>0.05$ ). The time course and range of chemotaxis indices are identical for each graph and its inset. Each data point represents the average of at least six independent assays using 100-200 animals per assay. Error bars equal S.E.M. allel for their responses to both the adapting odorant and to a second odorant assayed at a submaximal concentration.

\section{STATISTICAL ANALYSIS}

Statistical analyses were performed with the StatView 512+ program (McGraw-Hill). Pairwise comparisons were made using two-tailed $t$-tests. Multiple comparisons were made using ANOVA and Bonferroni $t$-tests.

\section{Results}

\section{STARVATION ENHANCES THE EXTENT OF ADAPTATION TO AN AWC-SENSED ODORANT}

The extent of olfactory adaptation in response to an odorant increases with amount of odorant

A

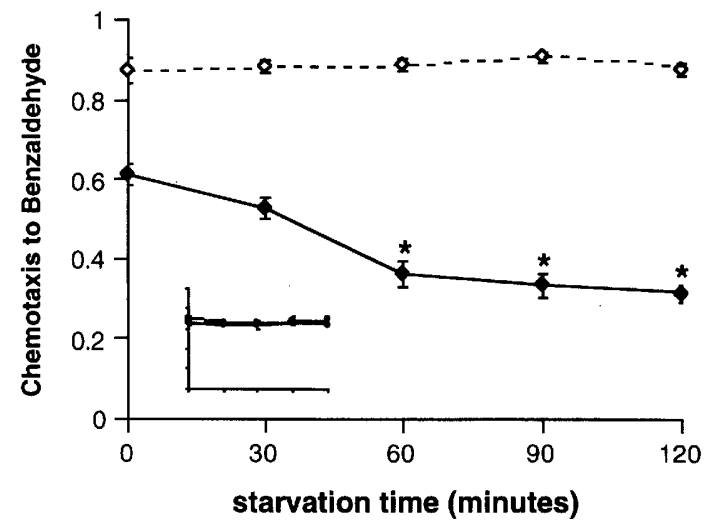

$\mathbf{B}$

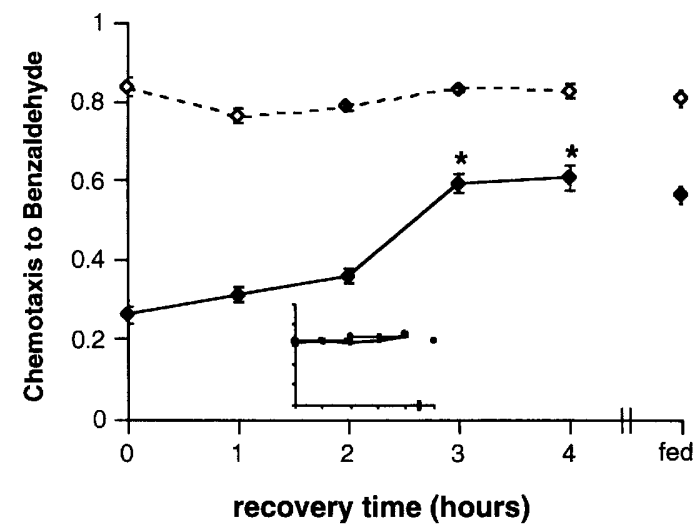


and with time of odorant exposure (Colbert and Bargmann 1995). In addition, wild-type animals adapted to benzaldehyde more completely when starved for an hour prior to odorant exposure (Fig. 1A). The effect of starvation on benzaldehyde adaptation followed a characteristic time course with a maximal effect on adaptation seen after approximately $1 \mathrm{hr}$ of starvation. Within $3 \mathrm{hr}$ of being returned to food, starved animals responded at the level of fed animals, indicating that animals can recover from this effect of starvation (Fig. 1B).

To determine whether starvation affects olfactory adaptation or olfactory acuity, unadapted animals were tested for their response to various dilutions of benzaldehyde (Fig. 2A). No effect of starvation on benzaldehyde sensitivity was seen in unadapted animals, suggesting that starvation modulates the process of olfactory adaptation rather than olfactory responsiveness.

Benzaldehyde is sensed by the AWC olfactory neurons (Bargmann et al. 1993). We were interested in determining whether starvation enhances adaptation to all AWC-sensed odorants. Adaptation to isoamyl alcohol was examined using the same starvation and adaptation conditions that revealed effects on benzaldehyde adaptation; under these conditions, starvation did not affect isoamyl alcohol adaptation (Fig. 2B). Thus, starvation modulates adaptation to some but not all AWC-sensed odorants.

Genetic and pharmacological manipulation of C. elegans has revealed potential pathways that regulate olfactory adaptation (Colbert and Bargmann 1995). The $a d p-1$ mutant, which is defective in adaptation to benzaldehyde, exhibited starva-

A

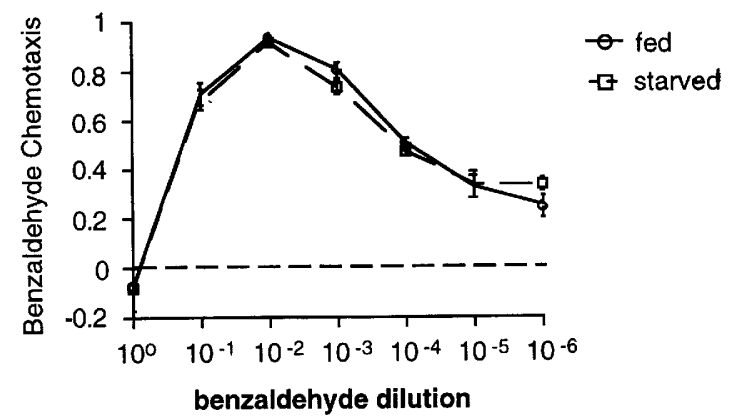

C

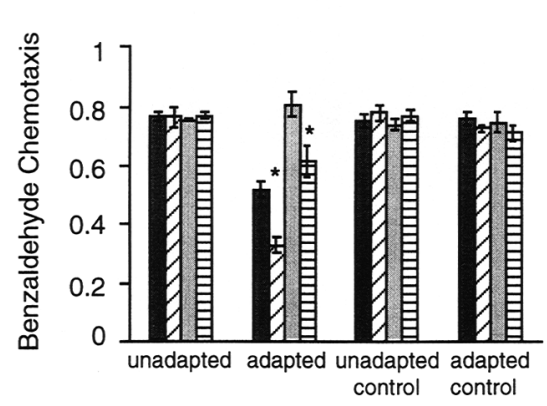
国 adp-1, fed
B

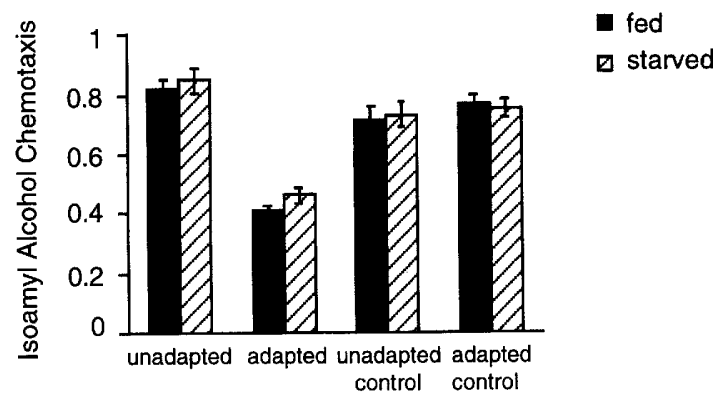

Figure 2: Starvation enhances adaptation to a subset of AWC-sensed odorants but does not affect olfactory responsiveness. (A) Starvation does not affect the benzaldehyde response of unadapted animals. Animals were starved (broken line) or fed (solid line) for 3 $\mathrm{hr}$; they were then assayed for their response to various dilutions of benzaldehyde. Starved and fed animals responded similarly to benzaldehyde at all dilutions tested (by $t$-test, 6 degrees of freedom for each data point: $10^{\circ}: t=0.166, P=0.87 ; 10^{-1}: t=0.468$, $P=0.66 ; 10^{-2}: t=1.85, P=0.11 ; 10^{-3}: t=1.78$, $P=0.13 ; 10^{-4}: t=0.89, P=0.41 ; 10^{-5}: t=0.072$, a wild-type, starved 口 adp-1, starved

$P=0.95 ; 10^{-6}: t=1.801, P=0.12$ ). (B) Starvation does not enhance adaptation to isoamyl alcohol. Animals were starved (hatched bars) or fed (solid bars) for $2 \mathrm{hr}$; they were then incubated with (adapted) or without (unadapted) isoamyl alcohol for $60 \mathrm{~min}$. Subsequently, they were assayed for their response to isoamyl alcohol or to the control odorant butanone (control). Starved and fed animals adapted similarly to isoamyl alcohol $(t=1.758,10$ degrees of freedom, $P=0.11) .(C)$ Adaptation of adp-1 mutants to benzaldehyde is modulated by starvation. Wild-type and adp- 1 mutant animals were starved or fed for $2 \mathrm{hr}$. They were then incubated with (adapted) or without (unadapted) benzaldehyde for $60 \mathrm{~min}$ and were subsequently assayed for their response to benzaldehyde or to the control odorant butanone (control). Starvation enhanced adaptation of adp-1 animals to benzaldehyde [marked with asterisk $\left(^{*}\right) ; t=2.818$ with 6 degrees of freedom, $P=0.03$ ]. Wild-type controls also exhibited enhanced adaptation. Each data point represents the average of at least three independent assays using 100-200 animals per assay. Error bars equal the S.E.M.

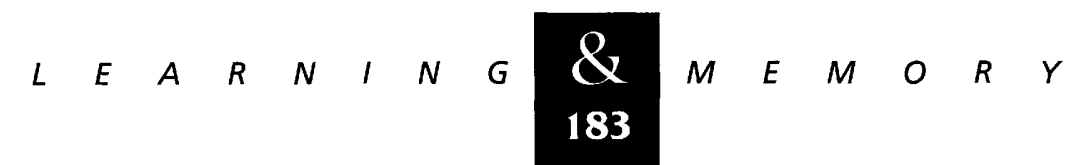


tion-induced enhancement of benzaldehyde adaptation (Fig. 2C). This result indicates that the adp-1 mutation does not block the adaptation process induced by starvation.

\section{EXOGENOUS SEROTONIN INHIBITS THE EFFECT OF STARVATION ON BENZALDEHYDE ADAPTATION}

Exogenous serotonin mimics the effects of feeding on multiple C. elegans behaviors (Horvitz et al. 1982; Avery and Horvitz 1990; Schafer and Kenyon 1995). We found that animals that were starved on serotonin-containing plates adapted to benzaldehyde like fed animals (Fig. 3A). However, if animals were first starved and then transferred to serotonin-containing plates, exogenous serotonin did not rescue the effect of prior starvation on benzaldehyde adaptation (Fig. 3B).

\section{A}

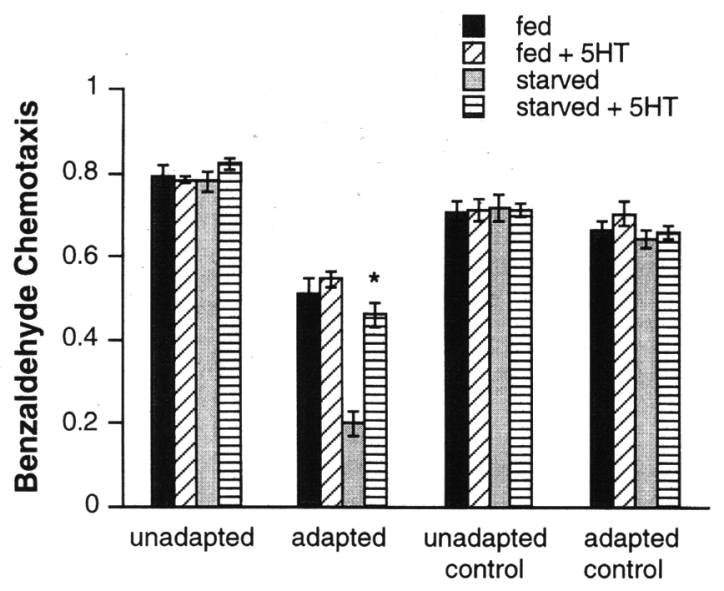

The biogenic amine octopamine has been detected in C. elegans by biochemical methods. Exogenous octopamine antagonizes the effect of serotonin on egg laying (Horvitz et al. 1982), whereas the octopamine antagonist phentolamine (Evans and O'Shea 1978) stimulates egg laying in $C$. elegans. No effect on benzaldehyde adaptation was seen when animals were starved on phentolamine-containing plates at a range of different concentrations (data not shown; see Materials and Methods).

\section{STARVATION INHIBITS RECOVERY FROM ADAPTATION TO AN AWA-SENSED ODORANT}

Starvation may enhance benzaldehyde adaptation by modulating adaptation directly; alternatively, it could act by inhibiting recovery from ad-

\section{B}

Figure 3: Serotonin inhibits starvation-induced enhancement of benzaldehyde adaptation. (A) Animals were maintained for $2 \mathrm{hr}$ with (fed) or without (starved) food and with $(+5 \mathrm{HT})$ or without exogenous serotonin; they were then incubated for $60 \mathrm{~min}$ with (adapted) or without (unadapted) benzaldehyde and were assayed for their response to benzaldehyde or to the control odorant butanone (control). Starved, serotonin-treated animals adapted less to benzaldehyde than starved controls [marked with asterisk $\left(^{*}\right) ; t=6.254$ with 20 degrees of freedom, $P<0.05$ by Bonferroni $t$-test] and behaved similarly to fed animals with regard to benzaldehyde adaptation $(t=2.165$ with 20 degrees of freedom; $P>0.05$ ). Exogenous serotonin $(5 \mathrm{~mm})$ was used for the incubations; this concentration is similar to that used to induce other behaviors in $C$. elegans, such as egg laying (Horvitz et al. 1982) and pharyngeal pumping (Avery and Horvitz 1990). (B) Animals were starved for $2 \mathrm{hr}$ and were then incubated for $3 \mathrm{hr}$ in the presence of food (fed), in the presence of serotonin (starved $+5 \mathrm{HT}$ ), or in the absence of food or serotonin (starved). They were then incubated with (adapted) or without (unadapted) benzaldehyde for $60 \mathrm{~min}$ and were subsequently assayed for their response to benzaldehyde or to the control odorant butanone (control). Animals that were starved and incubated with serotonin were indistinguishable from animals starved without serotonin ( $t=1.013$ with 15 degrees of freedom, $P>0.05$ by Bonferroni $t$-test) and distinct from unstarved animals $(t=6.949$ with 15 degrees of freedom; $P<0.05)$. Each data point represents the average of at least three independent assays using 100-200 animals per assay. Error bars indicate S.E.M.

$$
\text { ....... 圆"n.... }
$$


aptation. We found that animals that were adapted to benzaldehyde and then removed from odorant regained their benzaldehyde response similarly in the presence or absence of food (Fig. 4A). For this odorant, starvation appears to affect only the extent of adaptation and not recovery from adaptation.

A different effect of starvation was observed when adaptation to 2-methylpyrazine was examined. The odorant pyrazine is sensed by the AWA olfactory neurons (Bargmann et al. 1993), and analysis of AWA-defective mutants indicates that 2-methylpyrazine is most likely also sensed by the AWA neurons (H.A. Colbert and C.I. Bargmann, unpubl.; D. Tobin and K. Roayaie, pers. comm.).
Unlike most odorants, which require up to $1.5 \mathrm{hr}$ of odorant exposure for maximal adaptation (Colbert and Bargmann 1995), 2-methylpyrazine adaptation was complete within $10 \mathrm{~min}$ of odorant exposure (Fig. 4B; data not shown). 2-Methylpyrazine-adapted animals responded normally to the AWA-sensed odorant diacetyl and to several other odorants (Fig. 4B, inset; data not shown).

Recovery from adaptation to 2-methylpyrazine followed a time course similar to that of other odorants, with half-maximal recovery occurring within $60 \mathrm{~min}$ and full recovery occurring within 3 hr after termination of odorant exposure (Fig. 4B). 2-Methylpyrazine adaptation was so rapid that the effect of starvation on pyrazine adaptation could

A

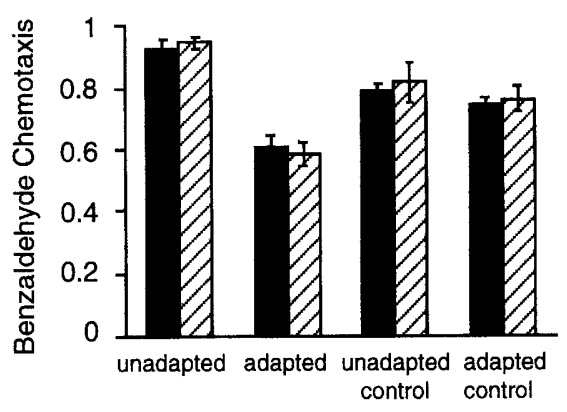

C

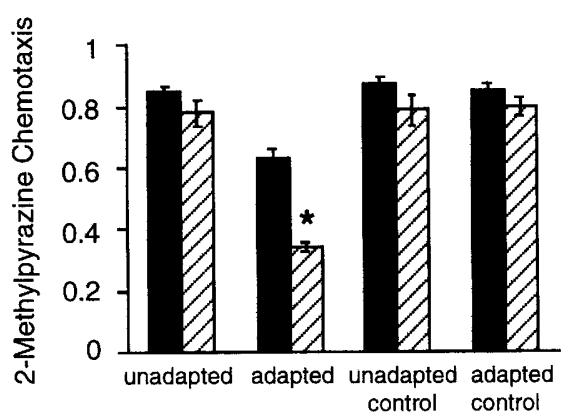

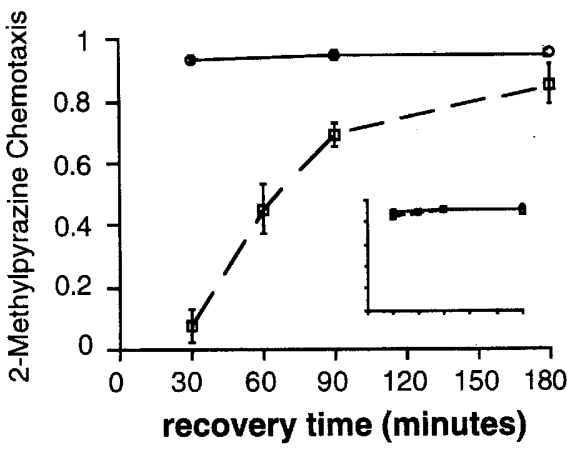

Figure 4: Starvation inhibits recovery from some forms of olfactory adaptation. (A) Starvation does not affect recovery from benzaldehyde adaptation. Animals were incubated with (adapted) or without (unadapted) benzaldehyde for $90 \mathrm{~min}$. They were then incubated for 45 min in the presence (solid bars) or absence (hatched bars) of food and were subsequently assayed for their response to benzaldehyde or to the control odorant butanone (control). Wild-type animals recover in $-2.5 \mathrm{hr}$, so this 45 -min time point could reveal either enhancement or suppression of recovery. Fed and starved animals recovered from benzaldehyde adaptation to a similar extent (by $t$-test: $t=0.472,10$ degrees of freedom, $P=0.647)$. (B) Recovery from 2-methylpyrazine adaptation. Wild-type animals were incubated for $10 \mathrm{~min}$ with (broken line) or without (solid line) 2-methylpyrazine and were then allowed to recover in the absence of odorant for various lengths of time. They were subsequently assayed for their responses to 2-methylpyrazine or to the control odorant diacetyl (inset). Recoveries were conducted in the presence of food. The time course and range of chemotaxis indices are identical for the graph and its inset. $(C)$ Starvation inhibits recovery from 2-methylpyrazine adaptation. Animals were incubated with (adapted) or without (unadapted) 2-methylpyrazine for 10 min; they were then allowed to recover for $90 \mathrm{~min}$ in the absence of odorant and in the presence (solid bars) or absence (hatched bars) of food. They were subsequently assayed for their response to 2-methylpyrazine or to the control odorant diacetyl (control). Recovery from 2-methylpyrazine adaptation was inhibited in starved animals relative to fed animals [marked with asterisk $\left.{ }^{*}\right)$; by $t$-test: $t=9.68,6$ degrees of freedom, $P<0.001$ ]. Each data point represents the average of at least three independent assays using 100-200 animals per assay. Error bars equal S.E.M. 
not be determined. However, starvation did affect recovery from 2-methylpyrazine adaptation (Fig. 4C); 90 min after termination of odorant exposure, starved animals had only recovered half as well as fed animals. For this odorant, starvation appears to inhibit recovery from olfactory adaptation, thereby extending olfactory memory.

\section{STARVATION ENHANCES OLFACTORY DISCRIMINATION}

Unadapted animals fail to respond to an odorant in the presence of high uniform concentrations of that odorant; this decrease in response is termed saturation (Bargmann et al. 1993). In some cases, an odorant can cross-saturate the response to a second odorant sensed by the same olfactory neuron; cross-saturation studies in humans have provided a means of odorant classification (Murphy 1987). Similarly, cross-saturation assays provide a measure of the ability of $C$. elegans to discriminate among various odorants. For example, the AWC-sensed odorants benzaldehyde and isoamyl alcohol reciprocally cross-saturate the other's response (Bargmann et al. 1993; Materials and Methods), indicating that these two odorants are poorly distinguished by $C$. elegans. We were interested in determining whether starvation affects the ability of wild-type animals to discriminate different odorants in this cross-saturation paradigm. We found that starvation enhanced the ability of benzaldehyde to saturate its own response but that it inhibited the ability of benzaldehyde to cross-saturate the isoamyl alcohol response of wild-type animals (Fig. 5A). Thus, starvation enhances the ability of animals to discriminate among odorants that normally cross-saturate with one another.

To determine whether starvation directly modulates the isoamyl alcohol response, starved and fed animals were assayed for their response to various dilutions of isoamyl alcohol (Fig. 5B). As was observed with benzaldehyde, starved and fed animals responded similarly to the odorant. Although starved animals appeared to be slightly more sensitive to isoamyl alcohol than fed animals at the $10^{-2}$ isoamyl alcohol dilution, this difference was too slight to account for the effect of starvation on cross-saturation.

The term cross-adaptation refers to a diminished response to one odorant following adaptation to another odorant; the mutant $a d p-1(k y 20)$ is partially defective in cross-adaptation of the iso- amyl alcohol response by benzaldehyde (Colbert and Bargmann 1995). We found that $a d p-1$ animals were also partially defective in cross-saturation of the isoamyl alcohol response by benzaldehyde, although the ability of benzaldehyde to saturate its own response was unaffected (Fig. 5C). Therefore, adp-1 animals exhibited enhanced olfactory discrimination in this assay. Because $a d p-1$ affects both cross-saturation and cross-adaptation, these two processes may share common components.

\section{ADAPTATION TO ONE ODORANT FACILITATES THE RESPONSE TO ANOTHER ODORANT SENSED BY THE SAME NEURON}

Human and rat psychophysical studies have indicated that, in addition to attenuating the response to cross-adapting odorants, adaptation to an odorant may also facilitate the response to noncross-adapting odorants (Engen 1982). To examine whether adaptation to an odorant might enhance the response to other odorants, animals adapted to isoamyl alcohol were assayed for their response to the odorant butanone. Butanone is sensed by the AWC neurons, but it does not cross-adapt with isoamyl alcohol or benzaldehyde (Colbert and Bargmann 1995). We found that adaptation to isoamyl alcohol led to an increased response to butanone at concentrations of butanone that elicited a submaximal response in unadapted animals (Fig. 6A). This effect of isoamyl alcohol adaptation was selective for butanone, as the response to the odorant diacetyl was not significantly affected by isoamyl alcohol adaptation (Fig. 6B).

\section{Discussion}

STARVATION ENHANCES OLFACTORY

ADAPTATION, MEMORY, AND DISCRIMINATION

Olfactory adaptation in C. elegans has properties characteristic of memory. Adaptation is a specific, lasting, but reversible behavioral modification in response to an animal's olfactory experience, that is not attributable to fatigue or injury (Dudai 1989). It depends on the activity of specific gene products, indicating that it is an active rather than a passive response to the presence of odorant (Colbert and Bargmann 1995). Here, we show that the context of odorant presentation affects adaptation: The same odorant stimulus elicits different effects

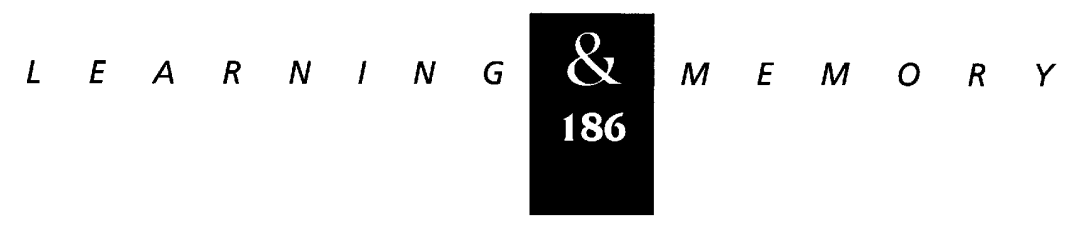


depending on whether an animal is well-fed or starved. As a result, future responses to the odorant depend not only on previous exposure to that odor but also on the animal's feeding state when the odor was encountered.

A brief period of starvation alters olfactory adaptation in several ways (Fig. 7). Starvation enhances adaptation to the odorant benzaldehyde, but it does not affect the olfactory response of unadapted animals to benzaldehyde. These results indicate that starvation specifically modulates the process of olfactory adaptation and not olfactory sensitivity. The effect of starvation on olfactory adaptation is antagonized by exogenous serotonin,

A

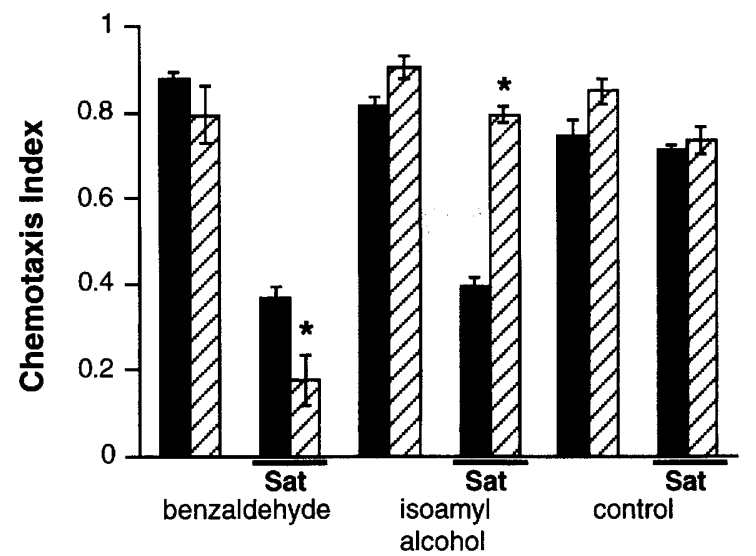

suggesting that serotonin may mediate the effect of feeding state on adaptation. Serotonergic neurons in C. elegans include the pharyngeal NSM neurons, which are thought to be neurosecretory in function (Albertson and Thomson 1976). Release of serotonin by the NSM neurons into the adjacent pseudocoelomic space could permit serotonin to modulate the activity of chemosensory neurons located in the head of the animal. Alternatively, the serotonergic ADF chemosensory neurons may mediate the effects of starvation on olfactory adaptation; $\mathrm{ADF}$ and the olfactory neurons AWA and AWC share common postsynaptic partners (White et al. 1986).
C

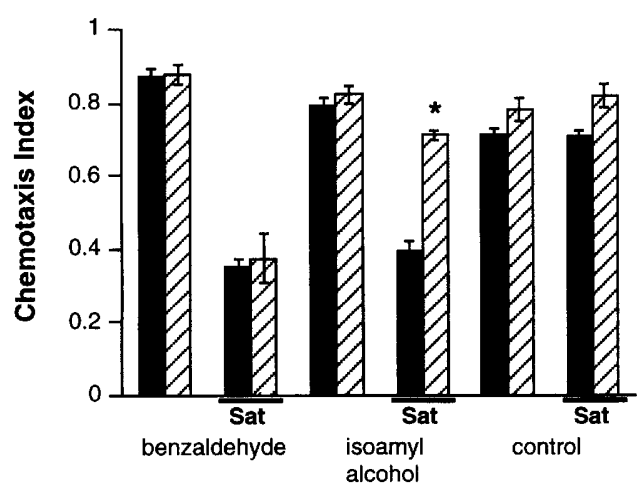

B

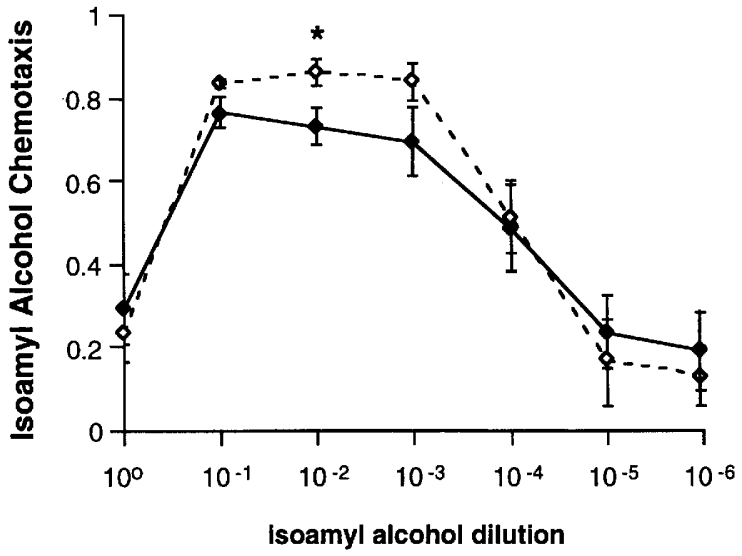

Figure 5: Olfactory discrimination is enhanced by starvation and by the $a d p-1(k y 20)$ mutation. (A) Starvation inhibits cross-saturation of isoamyl alcohol by benzaldehyde. Animals were incubated with (solid bars) or without (hatched bars) food for $2 \mathrm{hr}$. They were then assayed for their responses to benzaldehyde, isoamyl alcohol, or butanone (control), in the presence (marked by Sat) or absence of saturating concentrations of benzaldehyde. The benzaldehyde response of starved animals was saturated more completely than that of fed animals [marked with asterisk $\left({ }^{*}\right)$; by $t$-test: $t=3.097,10$ degrees of freedom, $P=0.011$ ]; cross-saturation of isoamyl alcohol by benzaldehyde was inhibited by starvation [marked with asterisk $\left({ }^{*}\right)$; by $t$-test: $t=14.379,10$ degrees of freedom, $\left.P<0.001\right]$. (B) Effect of starvation on chemotaxis to isoamyl alcohol. Animals were incubated with (solid line) or without (broken line) food for $2 \mathrm{hr}$ and then assayed for their responses to various dilutions of isoamyl alcohol. Starved and fed animals responded similarly to isoamyl alcohol at all dilutions tested except for $10^{-2}$ (by $t$-test, 10 degrees of freedom for each data point: $10^{0}: t=0.566$, $P=0.58 ; 10^{-1}: t=1.76, P=0.11 ; 10^{-2}: t=2.406, P=0.037 ; 10^{-3}: t=1.535, P=0.16 ; 10^{-4}: t=0.196, P=0.85 ; 10^{-5}$ : $t=0.527, P=0.61 ; 10^{-6}: t=0.503, P=0.63$ ). (C) Wild-type (solid bars) and adp-1(ky20) (hatched bars) animals were assayed for their responses to benzaldehyde, isoamyl alcohol, and butanone (control), in the presence (marked by Sat) or absence of saturating concentrations of benzaldehyde. The benzaldehyde response of adp- $1(\mathrm{ky} 20)$ animals saturated normally (by $t$-test: $t=0.339,10$ degrees of freedom, $P=0.74$ ); cross-saturation of the isoamyl alcohol response by benzaldehyde was diminished in adp-1(ky20) mutants [marked with asterisk $\left(^{*}\right)$; by $t$-test: $t=9.712,10$ degrees of freedom, $P<0.001]$. Each data point represents the average of at least six independent assays using 100-200 animals per assay. Error bars indicate S.E.M.

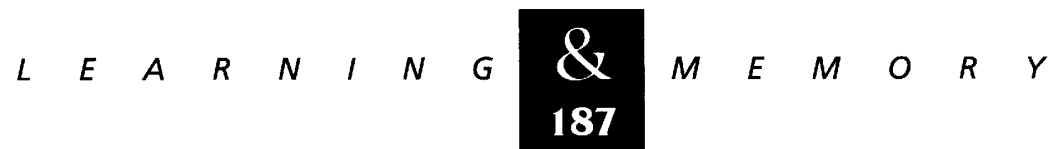


Starvation also potentiates adaptation to a second odorant, 2-methylpyrazine, but it does so by inhibiting recovery from adaptation. Adaptation to a third odorant, isoamyl alcohol, is not altered by starvation, but discrimination between this odorant and benzaldehyde is enhanced. These results indicate that starvation induces odorant-specific changes in C. elegans olfactory responses. It is striking that each odorant behaves so differently, especially because benzaldehyde and isoamyl alcohol are sensed by the same olfactory neurons. However, this observation is consistent with previous work showing that benzaldehyde and isoamyl alcohol adaptation have distinct genetic and pharmacological properties in unstarved animals (Colbert and Bargmann 1995).

\section{OLFACTORY DISCRIMINATION IS AN ACTIVE PROCESS}

Our results demonstrate that olfactory discrimination is a dynamic process, because enhanced discrimination is observed after starvation. Using only two pairs of olfactory neurons, the AWA and AWC neurons, C. elegans can discrimi-

$\mathbf{A}$ nate among at least seven classes of olfactory stimuli (Bargmann et al. 1993; Colbert and Bargmann 1995). This discrimination is possible because individual neurons in $C$. elegans express multiple chemosensory receptor genes (Fig. 7; Troemel et al. 1995; Sengupta et al. 1996). For example, the olfactory receptor Odr-10 allows the AWA neurons to sense the odorant diacetyl, whereas other receptor genes mediate responses to other AWA-sensed odorants (Sengupta et al. 1996). Olfactory discrimination in C. elegans may result from regulation of odorant receptors or other odorant-specific signal transduction components within olfactory neurons. More complex levels of sensory information processing might occur downstream of the sensory neuron, as has been proposed for the ASH sensory synapse (Hart et al. 1995; Maricq et al. 1995).

Unlike C. elegans neurons, vertebrate olfactory receptor neurons express only one or a few olfactory receptor genes (Ngai et al. 1993; Vassar et al. 1993); vertebrate olfactory discrimination is regulated at a later level of processing in the olfactory bulb (Mori and Shepherd 1994; Nakanishi 1995; Yokoi et al. 1995). The neurotransmitter glutamate is associated with increased olfactory discrimina-

B

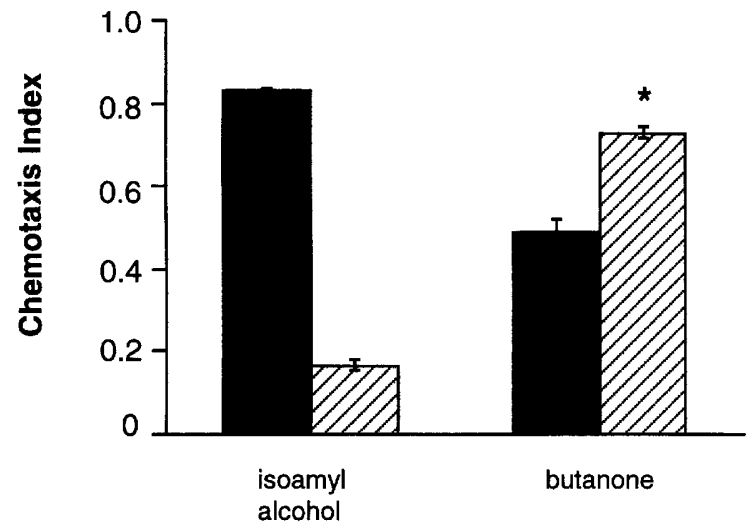

Figure 6: Odorant exposure can enhance olfactory acuity to other odorants sensed by the same olfactory neuron. $(A)$ Isoamyl alcohol adaptation enhances sensitivity to butanone. Animals were incubated with (hatched bars) or without (solid bars) isoamyl alcohol for $60 \mathrm{~min}$ and were assayed for their responses to isoamyl alcohol or to butanone (10 ${ }^{-4}$ dilution). Animals adapted to isoamyl alcohol exhibited an enhanced response to butanone, relative to unadapted animals [marked with asterisk $\left(^{*}\right)$; by $t$-test: $t=7.044,14$ degrees of freedom, $\left.P<0.001\right]$. $(B)$ Isoamyl alcohol adaptation does not affect the response to diacetyl. Animals were incubated with (hatched bars) or without (solid bars) isoamyl alcohol for 60 min and were assayed for their responses to isoamyl alcohol or to diacetyl $\left(10^{-4}\right.$ dilution). Adapted and unadapted animals responded similarly to diacetyl (by $t$-test: $t=0.972,10$ degrees of freedom, $P=0.35$ ). Each data point represents the average of at least three independent assays using 100-200 animals per assay. Error bars equal S.E.M.

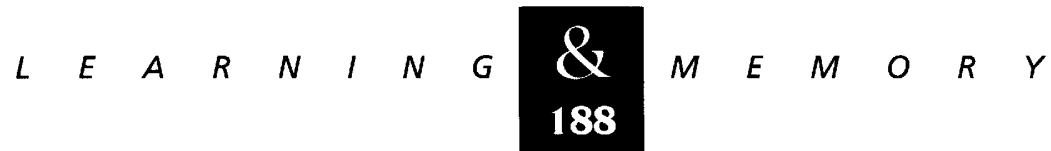



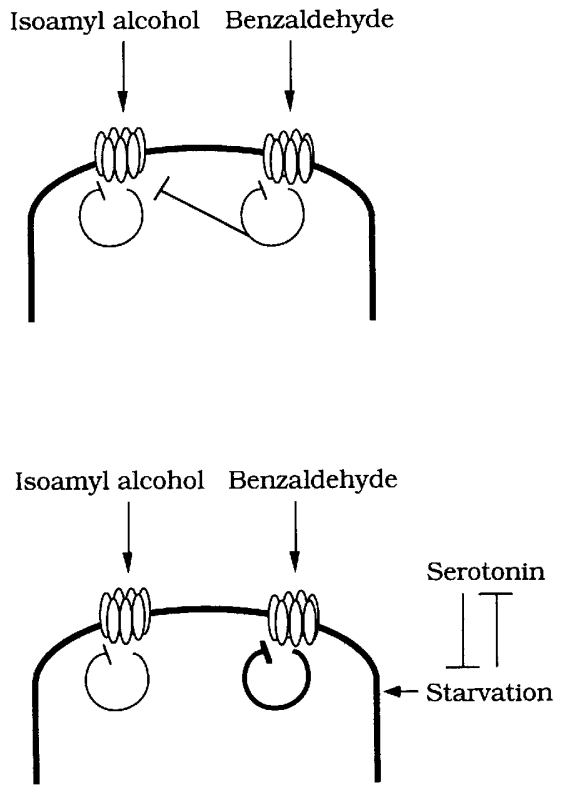

Figure 7: Modification of benzaldehyde responses by starvation. The AWC olfactory neurons respond to both benzaldehyde and isoamyl alcohol, probably via distinct $G$ protein-coupled receptors (Bargmann et al. 1993; Sengupta et al. 1996). (Top) Well-fed animals adapt after prolonged exposure to benzaldehyde or isoamyl alcohol, and these two responses cross-saturate (Bargmann et al. 1993; Fig. 5; Materials and Methods). (Bottom) After starvation, benzaldehyde adaptation is enhanced, but cross-saturation with isoamyl alcohol is blocked; these changes may occur within the sensory neuron, as drawn, or in downstream neurons. Serotonin antagonizes this effect of starvation.

tion (Yokoi et al. 1995) as well as olfactory memory in mice (Kaba et al. 1994) and sheep (Kendrick et al. 1992). Dopamine has also been implicated in modulation of discrimination, and olfactory deprivation in rats results in enhanced olfactory discrimination that is attributed to decreased dopamine levels (Wilson and Sullivan 1995).

\section{STARVED C. ELEGANS USE A "NOVELTY-SEEKING" OLFACTORY SEARCH STRATEGY}

C. elegans uses its sensitive olfactory system to detect bacteria, its principal food source (Grewal and Wright 1992; Bargmann et al. 1993). Different bacterial species have distinct odors (Zechman and Labows 1985), so an animal in a complex olfactory environment may be exposed to a variety of attractive odorants. Olfactory adaptation provides one mechanism for modulating olfactory preferences based on previous experience.

Both well-fed and starved animals adapt to olfactory stimuli, but starved animals show stronger, more specific changes in their behavior based on previous odorant experience. Starved animals exhibit increased olfactory adaptation and decreased recovery after adaptation to some odorants. At the same time, starvation enhances discrimination between odorants, so that adaptation of starved animals is more odorant-restricted than adaptation of well-fed animals. Furthermore, animals adapted to one odorant can exhibit increased sensitivity to another odorant.

These different forms of olfactory plasticity may act together to produce a change in an animal's olfactory search strategy depending on its feeding state. Well-fed animals are responsive to many odorants, although these responses are slowly altered through adaptation. Starved animals also respond to many odorants, but their preferences shift more strikingly based on their experience. For these animals, a novel, potentially informative odorant will be preferred to an odorant that did not lead the animal to food. As a result, starved animals are more likely to sample different environments, perhaps increasing their chances of finding food under stressful conditions.

\section{Acknowledgments}

We thank Mario de Bono and Allison Doupe for comments on this manuscript. This work was supported by grants from the Human Frontiers Science Program and the Howard Hughes Medical Institute. H.A.C. was partially supported by a University of California Chancellor's Fellowship. C.I.B. is an Assistant Investigator of the Howard Hughes Medical Institute.

The publication costs of this article were defrayed in part by payment of page charges. This article must therefore be hereby marked "advertisement" in accordance with 18 USC section 1734 solely to indicate this fact.

\section{References}

Albertson, D. and N. Thomson. 1976. The pharynx of Caenorhabditis elegans. Phil. Trans. R. Soc. Lond. B. Biol. Sci. 275: 299-325.

Avery, L. and H.R. Horvitz. 1990. Effects of starvation and neuroactive drugs on feeding in Caenorhabditis elegans. J. Exp. Zool. 253: 263-270.

Bargmann, C.I., E. Hartwieg, and H.R. Horvitz. 1993. Odorant-selective genes and neurons mediate olfaction in $C$. elegans. Cell 74: 515-527. 


\section{Colbert and Bargmann}

Brenner, S. 1974. The genetics of Caenorhabditis elegans. Genetics 77: 71-94.

Byrne, J.H. and E.R. Kandel. 1996. Presynaptic facilitation revisited: State and time dependence. J. Neurosci. 16: 425-435.

Colbert, H.A. and C.I. Bargmann. 1995. Odorant-specific adaptation pathways generate olfactory plasticity in $C$. elegans. Neuron 14: 803-812.

Croll, N. 1975. Indolealkylamines in the coordination of nematode behavioral activities. Can. J. Zool. 53: 894-903.

Delaney, K., D.W. Tank, and R.S. Zucker. 1991. Presynaptic calcium and serotonin-mediated enhancement of transmitter release at crayfish neuromuscular junction. J. Neurosci. 11: $2631-2643$.

Desai, C., G. Garriga, S.L. Mclntire, and H.R. Horvitz. 1988. A genetic pathway for the development of the Caenorhabditis elegans HSN motor neurons. Nature 336: 638-646.

Dudai, Y. 1989. The neurobiology of memory. Oxford University Press, Oxford, UK.

Dusenbery, D.B. 1980. Responses of the nematode Caenorhabditis elegans to controlled chemical stimulation. J. Comp. Physiol. 136: 327-331.

Engen, T. 1982. The perception of odors. Academic Press, San Diego, CA.

Epstein, L.H., A.R. Caggiula, K.A. Perkins, S.L. Mitchell, and J.S. Rodefer. 1992. Abstinence from smoking decreases habituation to food cues. Physiol. Behav, 52: 641-646.

Evans, P.D. and M. O' Shea. 1978. The identification of an octopaminergic neurone and the modulation of a myogenic rhythm in the locust. J. Exp. Biol. 73: 235-260.

Gelperin, A., L.D. Rhines, J. Flores, and D.W. Tank. 1993. Coherent network oscillations by olfactory interneurons: Modulation by endogenous amines. J. Neurophys. 69: 1930-1939.

Grewal, P.S. and D.J. Wright. 1992. Migration of Caenorhabditis elegans larvae towards bacteria and the nature of the bacterial stimulus. Fundam. Appl. Nematol. 15: $159-166$.

Hart, A.C., S. Sims, and J.M. Kaplan. 1995. Synaptic code for sensory modalities revealed by $C$. elegans GLR-1 glutamate receptor. Nature 378: 82-85.

Hedgecock, E.M. and R.L. Russell. 1975. Normal and mutant thermotaxis in the nematode Caenorhabditis elegans. Proc. Natl. Acad. Sci. 72: 4061-4065.

Horvitz, H.R., M. Chalfie, C. Trent, and P.D. Evans. 1982. Serotonin and octopamine in the nematode Caenorhabditis elegans. Science 216: 1012-1014.
Kaba, H., Y. Hayashi, T. Higuchi, and S. Nakanishi. 1994. Induction of an olfactory memory by the activation of a metabotropic glutamate receptor. Science 265: 262-264.

Kendrick, K.M., F. Levy, and E.B. Keverne. 1992. Changes in the sensory processing of olfactory signals induced by birth in sheep. Science 256: 833-836.

Kloppenburg, P. and J.G. Hildebrand. 1995.

Neuromodulation by 5 -hydroxytryptamine in the antennal lobe of the sphinx moth Manduca sexta. J. Exp. Biol. 198: 603-611.

Koelega, H.S. 1994. Diurnal variations in olfactory sensitivity and the relationship to food intake. Percept. Motor Skills 78: 215-226.

Liu, D.W. and J.H. Thomas. 1994. Regulation of a periodic motor program in C. elegans. J. Neurosci. 14: 1953-1962.

Loer, C.M. and C.J. Kenyon. 1993. Serotonin-deficient mutants and male mating behavior in the nematode Caenorhabditis elegans. J. Neurosci. 13: 5407-5417.

Maricq, A.V., E. Peckol, M. Driscoll, and C.I. Bargmann. 1995. Mechanosensory signalling in $C$. elegans mediated by the GLR-1 glutamate receptor. Nature 378: 78-81.

McLean, J.H., A. Darby-King, R.M. Sullivan, and S.R. King. 1993. Serotonergic influence on olfactory learning in the neonate rat. Behav. Neural Biol. 60: 152-162.

Mendel, J.E., H.C. Korswagen, K.S. Liu, Y.M. Hajdu-Cronin, M.I. Simon, R.H.A. Plasterk, and P.W. Sternberg. 1995. Participation of the protein $\mathrm{G}_{\mathrm{o}}$ in multiple aspects of behavior in C. elegans. Science 267: 1652-1655.

Mercer, A.R., J.H. Hayashi, and J.G. Hildebrand. 1995. Modulatory effects of 5-hydroxytryptamine on voltage-activated currents in cultured antennal lobe neurones of the sphinx moth Manduca sexta. J. Exp. Biol. 198: 613-627.

Mori, I. and Y. Ohshima. 1995. Neural regulation of thermotaxis in Caenorhabditis elegans. Nature 376: 344-348.

Mori, K. and G.M. Shepherd. 1994. Emerging principles of molecular signal processing by mitral/tufted cells in the olfactory bulb. Semin. Cell Biol. 5: 65-74.

Murphy, C. 1987. Olfactory psychophysics. In Neurobiology of taste and smell (ed. T.E. Finger and W.L. Silver), pp. 257-273. John Wiley and Sons, New York, NY.

Nakanishi, S. 1995. Second-order neurones and receptor mechanisms in visual- and olfactory-information processing. Trends Neurosci. 18: 359-364.

Ngai, J., A. Chess, M.M. Dowling, N. Necles, E.R. Macagno, and R. Axel. 1993. Coding of olfactory information: Topography of odorant receptor expression in the catfish olfactory epithelium. Cell 72: 667-680.

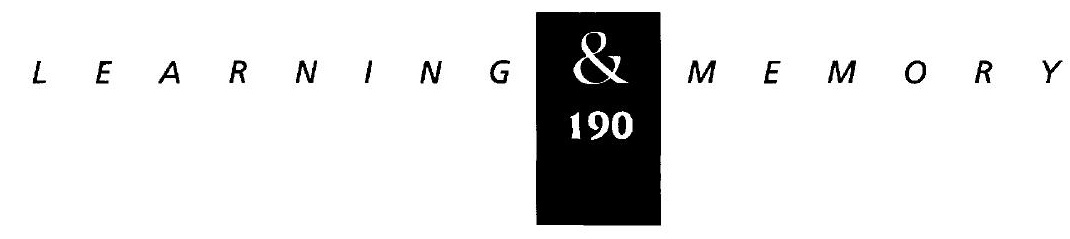


Rankin, C.H., C.D. Beck, and C.M. Chiba. 1990.

Caenorhabditis elegans: A new model system for the study of learning and memory. Behav. Brain Res. 37: 89-92.

Schafer, W.R. and C.J. Kenyon. 1995. A calcium-channel homologue required for adaptation to dopamine and serotonin in Caenorhabditis elegans. Nature 375: 73-78.

Segalat, L., D.A. Elkes, and J.M. Kaplan. 1995. Modulation of serotonin-controlled behaviors by $\mathrm{G}_{\mathrm{o}}$ in Caenorhabditis elegans. Science 267: 1648-1651.

Sengupta, P., J.H. Chou, and C.I. Bargmann. 1996. odr-10 encodes a seven transmembrane domain olfactory receptor required for responses to the odorant diacetyl. Cell 84: 899-909.

Trent, C. 1982. "Genetic and behavioral studies of the egg-laying system of Caenorhabditis elegans." Ph.D. thesis, Massachusetts Institute of Technology, Cambridge, MA.

Trent, C., N. Tsung, and H.R. Horvitz. 1983. Egg-laying defective mutants of the nematode Caenorhabditis elegans. Genetics 104: 619-647.

Troemel, E.R., J.H. Chou, N.D. Dwyer, H.A. Colbert, and C.I. Bargmann. 1995. Divergent seven transmembrane receptors are candidate chemosensory receptors in C. elegans. Cell 83: $207-218$

Vassar, R., J. Ngai, and R. Axel. 1993. Spatial segregation of odorant receptor expression in the mammalian olfactory epithelium. Cell 74: 309-318.

Ward, S. 1973. Chemotaxis by the nematode Caenorhabditis elegans: Identification of attractants and analysis of the response by use of mutants. Proc. Natl. Acad. Sci. 70: $817-821$.

Weinshenker, D., G. Garriga, and J.H. Thomas. 1995. Genetic and pharmacological analysis of neurotransmitters controlling egg laying in C. elegans. J. Neurosci. 15: 6975-6985.

White, J.G., E. Southgate, J.N. Thomson, and S. Brenner. 1986. The structure of the nervous system of the nematode $C$. elegans. Phil. Trans. R. Soc. Lond. B. Biol. Sci. 314: 1-340.

Wilson, D.A. and R.M. Sullivan. 1995. The D2 antagonist spiperone mimics the effects of olfactory deprivation on mitral/tufted cell odor response patterns. J. Neurosci. 15: 5574-5581.

Yokoi, M., K. Mori, and S. Nakanashi. 1995. Refinement of odor molecule tuning by dendrodendritic synaptic inhibition in the olfactory bulb. Proc. Natl. Acad. Sci. 92: 3371-3375.

Zechman, J.M. and J.N. Labows Jr. 1985. Volatiles of Pseudomonas aeruginosa and related species by automated headspace concentration-gas chromatography. Can. J. Microbiol. 31: 232-237.
Received January 2, 1997; accepted in revised form March 14, 1997. 


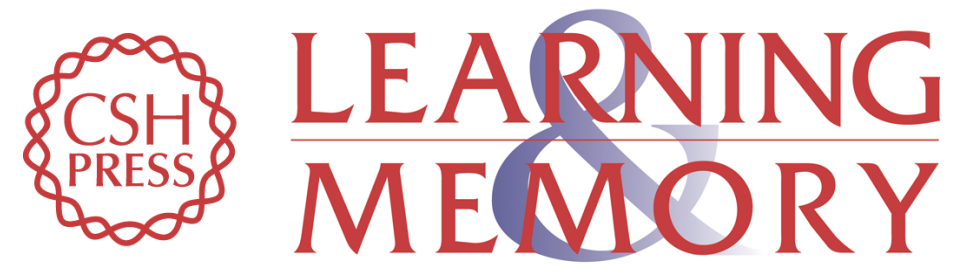

\section{Environmental signals modulate olfactory acuity, discrimination, and memory in Caenorhabditis elegans.}

H A Colbert and C I Bargmann

Learn. Mem. 1997, 4:

Access the most recent version at doi:10.1101//m.4.2.179

References This article cites 44 articles, 17 of which can be accessed free at:

http://learnmem.cshlp.org/content/4/2/179.full.htmI\#ref-list-1

License

Email Alerting Receive free email alerts when new articles cite this article - sign up in the box at the Service top right corner of the article or click here. 